\title{
Efficiency of insurance companies: Application of DEA and Tobit analyses
}

\section{Eva Grmanová}

Alexander Dubček University of Trencin

Trenčn, Slovak Republic

Email:eva.grmanova@tnuni.sk

\section{Herbert Strunz}

Alexander Dubček University of Trencin

Trenčn, Slovak Republic

Email:herbert.strunz@gmx.de

Abstract. The aim of this paper is to determine the relationship between technical efficiency and profitability of insurance companies. The profitability of insurance companies was expressed by such indicators as ROA, ROE and the size of assets. We analysed 15 commercial insurance companies in Slovakia in the period of 2013-2015. Technical efficiency scores were expressed using DEA models. The relationship between the technical efficiency score and the indicators of profitability was expressed using censored regression, i.e. the Tobit regression model and the Mann-Whitney U-test. The relationship between the technical efficiency score in the CCR and BCC models and all the groups formed on the basis of the return on assets and the group formed basing on the return on equity was not confirmed. Statistically significant difference between average technical efficiency score in the CCR model in the group of insurance companies with ROA $<1 \%, 2 \%$ ) and technical efficiency score in the CCR model in the group of insurance companies with ROA equal or higher than 2 was confirmed. Insurance companies with ROA equal or higher than 2 achieved greater average efficiency score in the CCR model than the group of insurance companies with ROA $<1 \%, 2 \%$ ).

Keywords: DEA models, efficiency score, Tobit regression, ROA, ROE.

JEL Classification: G22, C52

\section{INTRODUCTION}

Insurance market is an important segment of the economy in every country. Its positive development greatly affects country's economy. Commercial insurance companies belong to the most important actors at the insurance market. In the current era of globalization they operate within a very competitive environment. In order to be successful in such an environment they must carry out their activities efficiently. 
This is only possible if they compare their results with other insurance companies and constantly strive for dynamic development. In addition to efficiency, they must monitor many other indicators. The principal indicators are the indicators that characterize profitability. Profitability is crucial for an insurance company as it reflects its performance.

Efficiency is a relative indicator that reflects the results of a particular entity by means of comparing them with the results of other, similar entities. Profitability is expressed through the values of indicators of the subject analysed. However, efficiency and profitability are important for insurance companies in terms of achieving their goals. Determining the relationship between them can help management of an insurance company better manage its performance and better identify the tasks that must be accomplished in order to achieve the goals set by shareholders.

In the last decade, more studies have begun to address the issues of insurance companies' efficiency and the impact of various factors on this efficiency. However, only few of these studies concern Eastern European countries. The aim of this article is to expand geographically the knowledge in the field of ROA and ROE impacts on the level of technical efficiency of insurance companies.

\section{LITERATURE REVIEW}

First DEA model was published by Charnes, Cooper and Rhodes (1978). Since then, many studies evaluating efficiency of the commercial insurance companies around the world appeared. Extensive research of the commercial insurance companies' efficiency was present in Europe as well. Hussels and Ward (2007) evaluate the efficiency of the insurance companies in Germany and Great Britain. Delhausse et al. (1995) compare the efficiency in Belgium and France. Diacon, Starkey and O'Brien (2002) assess efficiency of the commercial insurance companies in fifteen European countries. Donni and Fecher (1997) evaluate the insurance companies' efficiency in the OECD countries.

Extensive research has led some authors to compare in their scientific papers the results of various research. Berger and Humphrey (1997) compare 130 studies on the efficiency of financial institutions in 21 countries. Similarly, Eling and Luhnen (2010) dealt with international comparison of the results of various scientific studies on the efficiency of insurance companies.

Research in the field of technical efficiency analysis of commercial insurance companies in the Slovak Republic is not extensive. Zimková (2015) assessed the efficiency of 13 commercial insurance companies in the Slovak Republic and assessed their super-efficiency in 2013. From the 13 insurance companies, 9 insurance companies were efficient. AXA Poist'ovňa, a.s. has achieved the greatest super-efficiency.

There are several techniques to determine the dependence between the technical efficiency score and other factors. One of the most important methods is Tobit regression. Tobit regression is rarely used to determine the relationship between the technical efficiency score of insurance companies and other factors. In the field of banking, however, there are several papers describing the application of Tobit regression. Xiping and Yuesheng (2007) applied DEA models and the Tobit regression model to analyse the efficiency of banks in China. Singh and Fida (2015) applied Tobit regression to analyse technical efficiency of banks in Oman. They assessed the impact of the bank's size, liquidity, profitability and capital adequacy on efficiency. In Europe, Batir, Volkman and Gungor (2017) address the efficiency of banks and the Tobit regression application when selected factors have an effect on efficiency. They compare the efficiency of participating banks and conventional banks. Participation banks are more efficient than conventional banks. An interesting conclusion of their research is that the impact of various factors depends on whether the banks are participatory or conventional. For instance, non-performing loans have a negative impact on efficiency for conventional banks but positive impact on the efficiency of participating banks. 
Several authors have dealt with identification of exogenous factors that affect the efficiency of insurance companies as well as with determining the relationship between the dependent variable - efficiency score of insurance companies and other external factors. Yakob et. al (2014) used DEA models and the Tobit regression model to identify exogenous factors affecting the efficiency of insurance companies in Malaysia from 2003 to 2007. This way, they identified factors affecting efficiency. When analysing management efficiency, the Tobit regression parameters for size and organizational form were statistically significant. When analysing investment management efficiency, the Tobit regression parameter for organizational form was statistically significant.

Exogenous factors include also the size of the subject analysed. The impact of size of an insurance company on its efficiency has been studied by several authors. Yao et al. (2007) used the DEA method to assess the efficiency of 22 insurance companies in China. They tested the hypothesis that large insurance companies are more efficient than small insurance companies. This hypothesis was based on the fact that small insurance companies have cheaper services but large insurance companies are more resistant to insolvency. Yao et al. (2007) also tested the hypothesis that state-owned insurance companies are less efficient than insurance companies that are not owned by the state. This assumption results from studies focusing on efficiency that did not focus on insurance companies. At the same time they dealt with the idea that insurance companies with direct sales that do not work through banking companies or intermediaries are more efficient. The impact of size expressed by logarithm of total assets was confirmed. Highly statistically significant was the parameter for the variable assessing distribution channels.

Similar research analysing the influence of various factors on the efficiency of the insurance companies is present also in Europe. Borges, Nektarios and Barros (2008), based on a survey by Greek life insurance companies, state that large and quoted life insurance companies are more efficient. Barros, Nektarios and Assaf (2010) conclude that the variable "big" has a negative influence on efficiency. On the other hand, logarithm of market share has a positive impact on efficiency. Logarithm of equity/invested assets has a negative influence on efficiency. Klumpes (2004) assessed the efficiency of 40 insurance companies in the UK that sold life insurance or pensions. They assessed the difference in efficiency of insurance companies based on their size. The subjects analysed were divided into two size categories.

Some authors deal with the relationship between efficiency of insurance companies and selected indicators of profitability. Huang and Eling (2013) concluded a positive relationship between profitability measured by the return on equity ROE and efficiency. They point out a positive relationship between the ratio of equity capital and total assets (SEA) and the efficiency score. They did not confirm the impact of the ratio of claims payments and premiums on efficiency. Branka and Mihelja (2013) compared the results of efficiency and the values of ROA of Croatian insurance companies and banks before, during and after the crisis. Inter alia, they noted that during the crisis financial institutions operated more efficiently but their accounting results of profitability were not better due to poorer market situation. ROA, ROE and the efficiency of life insurance companies were studied by Greene and Segal (2004). They note that cost inefficiency in the life insurance industry is negatively associated with return on equity. Jurčević and Žaja (2013) analyse the development of insurance companies and banks using Data Envelopment Analysis of Croatia in the period of financial crisis (2005-2010) and compare it with the development of ROA and ROE indicators. They say that insurance companies and banks work more efficiently during the crisis; however they achieve the lowest ROA and ROE figures in 2009 as well. This is because accounting ratios cannot be as good as during the boom due to deteriorated marker. 


\section{AIM, HYPOTHESES AND DATA}

\subsection{Aim of study and research hypotheses}

In our paper we will focus on the relationship between the efficiency of insurance companies and selected indicators of profitability. The aim of the paper is to determine the relationship between technical efficiency and profitability of insurance companies.

Thus, the article focuses not only on the characteristics of individual indicators but analyses the relationship between them. Profitability was expressed by the absolute indicator, the amount of total assets, and by relative indicators, return on assets (ROA) and return on equity (ROE). The amount of total assets is also used as an indicator characterizing the size of the insurance company.

The main research hypothesis is that there is a significant relationship between efficiency and profitability of insurance company.

Efficiency was characterized by the technical efficiency score expressed using DEA models. The relationship between the indicators was determined by the Tobit regression model. Mann-Whitney $U$ test is used for hypothesis testing.

The structure of the paper is following. The next sections describe data and the methodology used DEA models, the Tobit regression model and Mann-Whitney U test. This section is followed by data presentation and empirical analysis, which includes the expression of the technical efficiency score and parameters of Tobit regression expressing the relationship between technical efficiency and indicators of profitability. The last section includes a discussion and conclusions.

\subsection{Data}

On Slovak insurance market, there are 38 insurance undertakings and branches of foreign insurance undertakings. The subject of the analysis was 15 commercial insurance companies in Slovakia in the period 2013-2015. The technical efficiency score was expressed using two models: the input-oriented CCR model and the output-oriented BCC model. The inputs were claims incurred and operating expenses. The outputs were earned premiums and investment income.

In addition to indicators on the input and output side we also used the indicators of profitability and the absolute indicator of the size of assets and the relative indicators - return on assets (ROA) and return on equity (ROE). ROA is the ratio of net profit of the insurance company and its total assets. It shows how efficiently the assets are being using. The higher the value of the indicator, is the more favourable the insurance company's rating. ROE is the ratio of net profit of an insurance company and its equity. The value of ROE is important for shareholders as it expresses the return on the capital of the shareholders.

According to the values of ROA insurance companies were divided into three groups: insurance companies with ROA less than $1 \%$, insurance companies with ROA at the interval $<1 \%, 2 \%$ ) and insurance companies with ROA equal to or higher than $2 \%$. Based on ROE insurance companies were divided into two groups: insurance companies with ROE less than $5 \%$ and insurance companies with ROE equal to or higher than $5 \%$. The relationship between the indicators of insurance companies in the Slovak Republic can, inter alia, be assumed on the basis of results of scientific research dealing with the relationship between bank indicators.

Data were drawn from the annual reports of insurance companies (2013), annual reports (2015) and from the database Finstat (2015). Thus, different sources were used, which can lead to certain distortions.

The methods used in the paper are descriptive statistics, correlation analysis, Tobit regression, MannWhitney U test and Data envelopment analysis models (DEA models). 


\section{METHODOLOGICAL APPROACH}

\subsection{DEA models}

DEA models are quantitative models used to express relative efficiency score. They use linear programming to transform multiple inputs into multiple outputs. They construct a non-parametric data envelopment that is convex. The subjects analysed that are part of the data envelopment have an efficiency score equal to one or $100 \%$. The subjects analysed that are not part of the data envelopment are inefficient. Their efficiency is expressed by the ratio of the efficiency score relative to the data envelopment.

There are several types of DEA models. CCR and BCC models are the basic types. CCR models are based on the assumption of constant returns to scale. BCC models are based on the assumption of variable returns to scale.

Assuming that we have $n$ homogenous DMUs $U_{1}$ to $U_{n}$ and that we observe $m$ inputs, $r$ outputs and $\mathbf{X}=\left\{x_{i j}, i=1 \ldots m, j=1 \ldots n\right\}$ is the matrix of inputs, $\mathbf{Y}=\left\{y_{i j}, i=1, \ldots, r, j=1, \ldots, n\right\}$ is the matrix of outputs.

The efficiency score $\theta_{q}$ in the BCC model is the solution of the linear programming task

$$
\begin{array}{ll}
\text { minimize } & z=\theta_{q}-\varepsilon\left(\mathbf{e}^{T} \mathbf{s}^{*}+\mathbf{e}^{T} \mathbf{s}^{-}\right), \\
\text {under conditions } & \mathbf{X} \lambda+\mathbf{s}^{-}=\theta_{q} \mathbf{x}_{q}, \\
\mathbf{Y} \lambda-\mathbf{s}^{+}=\mathbf{y}_{q}, \\
\mathbf{e}^{T} \lambda=1, \\
\lambda, \mathbf{s}^{+}, \mathbf{s}^{-} \geq 0,
\end{array}
$$

where $\theta_{q}$ expresses the efficiency score of the $\operatorname{DMU} U_{q}, \mathbf{s}^{+}, \mathbf{s}^{-}$are deviation variables, $\boldsymbol{\lambda}$ is the matrix of weights, $\mathbf{e}^{T}=(1,1 . ., 1), \varepsilon$ is the infinitesimal constant.

(Jablonský and Dlouhý, 2004).

The technical efficiency score $\theta_{q}$ in the CCR model is expressed as (1)-(3) and (5).

One of the most important characteristics of DEA models is that for inefficient subjects it is possible to express how much their inputs would have to decrease or how much their outputs would have to increase in order to become efficient. This information is important for the management as it shows whether it is necessary to change the size when compared with other subjects.

\subsection{Tobit regression and Mann-Whitney $U$ test}

As in input-oriented DEA models the technical efficiency scores have values at the interval $\langle 0,1\rangle$, the type of regression for a limited dependent variable is used to determine the relationship between the score and other factors. Most often applied in practical tasks is the so called censored regression, known as Tobit regression. The use of classical regression may lead to distorted results since the condition of the leastsquares, which is used to estimate the parameters of the regression model, is not met. The standard Tobit regression model is $Y_{i}$ for the dependent variable and $X_{i}$ for the independent variable, characterized as:

$$
Y_{i}=\beta^{T} X_{i}+\varepsilon_{i}, \quad \varepsilon_{i} \sim N\left(0, \sigma^{2}\right)
$$


The Mann-Whitney $U$ test is used to compare difference between average of two independent groups. It is non-parametric test. The Mann-Whitney $U$ test is alternative to independent sample t-test.

\section{EMPIRICAL ANALYSIS}

\subsection{Analysis of efficiency}

First, we expressed descriptive characteristics of the indicators of insurance companies. The values are listed in Table 1.

Table 1

Descriptive statistics of insurance companies' indicators

\begin{tabular}{|c|c|c|c|c|c|c|}
\hline \multirow[t]{2}{*}{ Indicators } & \multicolumn{3}{|c|}{ Average } & \multicolumn{3}{|c|}{ Standard deviation } \\
\hline & 2013 & 2014 & 2015 & 2013 & 2014 & 2015 \\
\hline $\begin{array}{l}\text { Claims incurred (thousand } \\
\text { EUR) }\end{array}$ & 69700.9 & 70896.3 & 70756.7 & 97140.4 & 86302.8 & 85207.5 \\
\hline $\begin{array}{ll}\text { Operating } & \text { expenses } \\
\text { (thousand EUR) } & \\
\end{array}$ & 36324.5 & 36803.8 & 38530.8 & 46536.0 & 46722.5 & 47815.7 \\
\hline $\begin{array}{l}\text { Earned premiums } \\
\text { (thousand EUR) }\end{array}$ & 105222.7 & 104539.5 & 106579.0 & 139459.6 & 134429.1 & 132653.7 \\
\hline $\begin{array}{ll}\text { Investment } & \text { income } \\
\text { (thousand EUR) } & \\
\end{array}$ & 10998.7 & 12968.4 & 10145.5 & 16388.1 & 18695.9 & 15790.7 \\
\hline $\mathrm{ROE}(\%)$ & 9.9467 & 9.7800 & 8.6400 & 6.0644 & 6.5219 & 8.1440 \\
\hline $\operatorname{ROA}(\%)$ & 2.4867 & 2.4667 & 2.1933 & 2.5168 & 2.3542 & 2.1124 \\
\hline Assets (thousand EUR) & 409396.2 & 430279.3 & 434601.3 & 590883.3 & 604869.6 & 591236.0 \\
\hline
\end{tabular}

Source: own processing in Statistica

In 2013, insurance companies had the highest average value of ROA and ROE. In 2014, insurance companies had the highest average value of claims incurred and investment income. In 2015, insurance companies had the highest average value of operating expenses, earned premiums and the amount of assets. The variability of indicators was high. Standard deviation should, except for ROE and ROA in the years 2014 and 2015, have higher values than the average of indicators.

Next, we used the program EMS to express the technical efficiency score in CCR and BCC models. Values of descriptive characteristics of the technical efficiency scores in the period 2013-2015 are listed in Table 2 .

Based on the values of descriptive characteristics we may conclude that the highest average technical efficiency score in the CCR model was in 2013 and 2015. The highest average technical efficiency score in the BCC model was in 2013 and 2015 too. The greatest variability in the technical efficiency scores in the CCR and BCC models expressed as standard deviation was in 2014. The largest number of efficient insurance companies in the CCR and BCC models was in 2013.

In all three years CCR efficient insurance companies were: NN Životná poist'ovňa, a.s. and AEGON Životná poist'ovňa, a.s. 
Descriptive statistics of efficiency score

\begin{tabular}{lccc}
\hline Efficiency score & $\begin{array}{c}\text { Number of efficient } \\
\text { insurance company }\end{array}$ & $\begin{array}{c}\text { Average of } \\
\text { efficiency score }\end{array}$ & $\begin{array}{c}\text { Standard deviation of } \\
\text { efficiency score }\end{array}$ \\
\hline CCR model - 2013 & 6 & 0.86 & 0.16 \\
\hline BCC model - 2013 & 11 & 0.92 & 0.13 \\
\hline CCR model - 2014 & 3 & 0.83 & 0.23 \\
\hline BCC model - 2014 & 9 & 0.91 & 0.14 \\
\hline CCR model - 2015 & 4 & 0.86 & 0.18 \\
\hline BCC model - 2015 & 9 & 0.92 & 0.12 \\
\hline
\end{tabular}

Source: own processing in Statistica

In all three years BCC efficient insurance companies were: Allianz-Slovenská poist'ovňa, a.s., NN Životná poist'ovňa, a.s., KOMUNÁLNA poist'ovňa, a.s. Vienna Insurance Group, KOOPERATIVA poist'ovňa, a.s., Vienna Insurance Group, Poštová poist’ovňa, a.s., Poist'ovňa Slovenskej sporitel’ne, a.s. Vienna Insurance Group, Rapid life životná poist'ovňa, a.s. and AEGON Životná poist’ovňa, a.s.

NN Životná poist'ovňa, a.s. and AEGON Životná poist'ovňa, a.s. are efficient of scale. In a long term, the insurance companies do not have to increase or decrease their inputs. The other insurance companies should focus on the adjustment of their inputs.

\subsection{Relationship between efficiency and profitability}

A condition in Tobit regression is not a strong correlation between the dependent and independent variables. Thus, it can be seen from the values of the correlation coefficients that this condition was met. The strongest dependence (Table 3) between dependent and independent variables is between the rate of efficiency in CCR model and the values of ROE (0.3881).

Table 3

Correlation matrix

\begin{tabular}{lccccc}
\hline & CCR & BCC & ROA & ROE & Assets \\
\hline CCR & 1 & 0.6039 & 0.2731 & $0.3881^{* *}$ & 0.2157 \\
\hline BCC & 0.6039 & 1 & 0.2504 & 0.1528 & 0.1656 \\
\hline ROA & 0.2731 & 0.2504 & 1 & 0.6657 & -0.0398 \\
\hline ROE & $0.3881^{* *}$ & 0.1528 & 0.6657 & 1 & 0.2097 \\
\hline Assets & 0.2157 & 0.1656 & -0.0398 & 0.2097 & 1 \\
\hline
\end{tabular}

Source: own processing in Statistica

Dependent variable: CCR score of efficiency

The values of the technical efficiency score obtained using the CCR model were used as the dependent variable in Tobit regression. We assumed that the technical efficiency score $\theta$ in the CCR model would be linearly dependent on the values of ROA, ROE and the amount of assets (A). Thus, that the following relationship applies to the $j^{\text {th }}$ insurance company

$$
\theta_{j}=\beta_{0}+\beta_{1} R O A_{j i}+\beta_{2} R O E_{j i}+\beta_{3 i} A_{j i}+\varepsilon_{j} .
$$

The parameters $\beta_{1}, \beta_{2}, \beta_{3}$ of Tobit regression were estimated using the program Matrixer. 
Based on the resulting values of Tobit regression coefficients and p-levels of the estimated coefficients, as listed in Table 4, we came to the conclusion that the coefficients were not statistically significant. The assumption has not been confirmed.

Table 4

Tobit regression with dependent variable CCR score

\begin{tabular}{lccc}
\hline \multicolumn{1}{c}{ Coefficient of determination: $\mathbf{1 7 . 2 5 \%}$} & Coefficient & t-statistic & Sign. \\
\hline Constant & 0.7331 & 16.142 & 0.0000 \\
\hline ROA & 0.0063 & 0.4073 & 0.8864 \\
\hline ROE & 0.0084 & 1.5911 & 0.0507 \\
\hline Assets & 0.0000 & 9.4868 & 0.2856 \\
\hline
\end{tabular}

Source: own processing in Matrixer

Next, we investigated whether after dividing insurance companies into subgroups based on their values of ROA and ROE there would be a statistically significant difference between the technical efficiency scores of insurance companies in the subgroups. To test this hypothesis, we will use the Tobit regression with the dummy variables. Their number is the number of groups minus one. In case of two groups, the expression of Tobit regression for the $j^{\text {th }}$ insurance company is

$$
\theta_{j i}=\beta_{0}+\beta_{1} X_{2 j i}+\varepsilon_{j}
$$

where $\theta_{j i}$ is the technical efficiency score for the $\mathrm{j}^{\text {th }}$ insurance company in the $\mathrm{i}^{\text {th }}$ year, $\beta_{0} \beta_{1}$ are the parameters of the regression model, $X_{2 j i}=1$ if the insurance companies belong to the second group, otherwise $X_{2 j i}=0$.

In case of three groups, the expression of Tobit regression for the $j^{\text {th }}$ insurance company is

$$
\theta_{j i}=\beta_{0}+\beta_{1} X_{1 j i}+\beta_{2} X_{2 j i}+\varepsilon_{j},
$$

$X_{1 j i}=1$ if the insurance companies belong to the first group, otherwise $X_{1 j i}=0$.

$X_{2 j i}=1$ if the insurance companies belong to the second group, otherwise $X_{2 j i}=0$.

By using dummy variables in Tobit regression it is possible to test whether there is a statistically significant difference between average of the technical efficiency scores of insurance companies in the groups. Interpretation of coefficient of Tobit regression results is according to Fandel (2001).

We will test the statistical hypotheses

1HO: there is no statistically significant difference between averages of the technical efficiency scores of insurance companies in groups formed on the basis of their values of return on equity, i.e. the efficiency of the insurance companies is not affected by the group of return on equity.

2HO: there is no statistically significant difference between averages of the technical efficiency scores of insurance companies in groups formed on the basis of their values of return on assets, i.e. the efficiency of the insurance companies is not affected by the group of return on assets.

versus the following two-sided alternative hypotheses 
1H1: there is a statistically significant difference between averages of the technical efficiency scores of insurance companies in groups formed on the basis of their values of return on equity, i.e. the efficiency of insurance companies is affected by the group of return on equity.

2H1: there is a statistically significant difference between averages of the technical efficiency scores of insurance companies in groups formed on the basis of their values of return on assets, i.e. the efficiency of insurance companies is affected by the group of return on assets.

The coefficients of Tobit regression (Table 5) with dummy variables according to ROA groups are statistically significant. Insurance companies with ROA higher than $2 \%$ (inclusive) have an average technical efficiency score of 0.9298 . The average of technical efficiency score of insurance companies with ROA less than $1 \%$ is by 0.2151 lower compared to insurance companies with ROA equal or higher than $2 \%$. The average of technical efficiency score of insurance companies with ROA at the interval $<1 \%, 2 \%$ ) is by 0.1284 lower compared to insurance companies with ROA equal or higher than $2 \%$. The highest average technical efficiency score was achieved by insurance companies in the group with the largest values of ROA. The lowest average technical efficiency score was achieved by the group with the lowest values of ROA.

Table 5

Tobit regression with dependent variable CCR score

\begin{tabular}{lccc}
\hline Coefficient of determination: $\mathbf{2 0 . 8 0} \%$ & Coefficient & t-statistic & Sign. \\
\hline Constant & 0.9298 & 26.3619 & 0.0000 \\
\hline ROA less than $1 \%$ & -0.2158 & -3.1598 & 0.0030 \\
\hline ROA $\langle\mathbf{1 \%}, \mathbf{2} \%)$ & -0.1284 & -2.3184 & 0.0255 \\
\hline
\end{tabular}

Source: own processing in Matrixer

The shape of the regression function with dummy variables expressing the groups of insurance companies based on ROA is

$$
\theta_{j i}=0.9298-0.2158 X_{1 j i}-0.1284 X_{2 j i}+\varepsilon_{j},
$$

$X_{1 j i}=1$ if the insurance companies belong to the group with ROA less than $1 \%$, otherwise $X_{1 j i}=0$

$X_{2 j i}=1$ if the insurance companies belong to the group with ROA at the interval $\langle 1 \%, 2 \%)$, otherwise $X_{2 j i}=0$

$\theta_{j i}$ is efficiency score in CCR model.

However, coefficient of determination of this model is $20.80 \%$. We used the non-parametric MannWhitney $U$ test to assess the relevance of the statistical significance of the difference between the averages technical efficiency scores of the individual groups. The results are shown in Table 6. The first group includes insurance companies with ROA less than $1 \%$, the second group includes insurance companies with ROA $\langle 1 \%, 2 \%$ ) and the third group includes other insurance companies.

From Table 6 it can be said, that statistically significant difference between the averages technical efficiency scores group 1 and group 2 as well as group 1 and group 3 was not confirmed. The statistically significant difference between the averages technical efficiency scores group 2 and group 3 was confirmed (significance level 0.05). 
Mann-Whitney U test

\begin{tabular}{lcc}
\hline & U & Sign. \\
\hline Group 1 vs. group 2 & 55 & 0.7469 \\
\hline Group 1 vs. group 3 & 78 & 0.6391 \\
\hline Group 2 vs. group 3 & 100 & 0.0444 \\
\hline
\end{tabular}

Source: own processing in Statistica

The coefficients of Tobit regression with dummy variables based on ROE values are statistically significant. It follows from the results of Tobit regression (Table 7) that the average technical efficiency score of insurance companies with ROE higher than 5\% (inclusive) is by 0.8778 , the average technical efficiency score of insurance companies with ROE less than $5 \%$ is by 0.1638 lower.

Tobit regression with dependent variable CCR score

\begin{tabular}{lccc}
\hline \multicolumn{1}{c}{ Coefficient of determination: $\mathbf{1 1 . 3 4 \%}$} & Coefficient & t-statistic & Sign. \\
\hline Constant & 0.8778 & 30.5028 & 0.0000 \\
\hline ROE less than $5 \%$ & -0.1638 & -2.3994 & 0.0209 \\
\hline
\end{tabular}

Source: own processing in Matrixer

The shape of the regression function with dummy variables expressing the groups of insurance companies based on ROE is

$$
\theta_{j i}=0.8778-0.1638 X_{1 j i}+\varepsilon_{j}
$$

$X_{1 j i}=1$ if the insurance companies belong to the group with ROE less than $5 \%$, otherwise $X_{1 j i}=0$.

$\theta_{j i}$ is efficiency score in CCR model.

Coefficient of determination is however $11.34 \%$. To assess the relevance of the statistical significance of the difference between the averages technical efficiency scores of the individual groups, we used the nonparametric Mann-Whitney $\mathrm{U}$ test. The results are displayed Table 8.

Table 8

Mann-Whitney U test

\begin{tabular}{lcc}
\hline & U & Sign. \\
\hline Group 1 vs. group 2 & 133 & 0.6561 \\
\hline
\end{tabular}

Source: own processing in Statistica

From the results in the Table 8 we can state that the statistically significant difference between average technical efficiency scores has not been confirmed.

The null hypotheses stating that the efficiency of insurance companies in the CCR model is influenced by all groups formed based on the return on assets and the group formed based on the return on equity has not been confirmed. Insurance companies in groups formed based on the values of ROA have a statistically 
significant difference in the averages technical efficiency score in the group with ROA $<1 \%, 2 \%)$ and in the group with ROA equal or higher than 2 in the CCR model.

\section{Dependent variable: BCC score of efficiency}

The values $\theta_{j}$ of the technical efficiency score obtained in the BCC model were used as the dependent variable in Tobit regression. We assumed that the following relationship is true for $j^{\text {th }}$ insurance company

$$
\theta_{j i}=\beta_{0}+\beta_{1} R O A_{j i}+\beta_{2} R O E_{j i}+\beta_{3 i} A_{j i}+\varepsilon_{j} .
$$

Based on the resulting values of Tobit regression coefficients and the p-levels of the estimated coefficients, as listed in Table 9, we may conclude that the coefficients are not statistically significant. The assumption has not been confirmed.

Table 9

Tobit regression with dependent variable BCC score

\begin{tabular}{lccc}
\hline \multicolumn{1}{c}{ Coefficient of determination: $\mathbf{9 . 9 7 \%}$} & Coefficient & t-statistic & Sign. \\
\hline Constant & 0.8753 & 0.0331 & 0.0000 \\
\hline ROA & 0.0191 & 0.0112 & 0.0972 \\
\hline ROE & -0.0021 & 0.0038 & 0.5828 \\
\hline Assets & 0.0000 & 3.3634 & 0.1835 \\
\hline
\end{tabular}

Source: own processing in Matrixer

The results of Tobit regression (Table 10) with dummy variables by groups of ROA show that there is no statistically significant coefficient for the group of insurance companies less than $1 \%$.

Table 10

Tobit regression with dependent variable BCC score

\begin{tabular}{lccc}
\hline \multicolumn{1}{c}{ Coefficient of determination: $\mathbf{3 1 . 2 8 \%}$} & Coefficient & t-statistic & Sign. \\
\hline Constant & 0.9733 & 42.4345 & 0.0000 \\
\hline ROA less than $1 \%$ & -0.0082 & -0.1847 & 0.8544 \\
\hline ROA $\langle\mathbf{1 \% , 2 \% )}$ & -0.1560 & -4.3312 & 0.0001 \\
\hline
\end{tabular}

Source: own processing in Matrixer

After dividing insurance companies into two groups, i.e. insurance companies with ROA less than $2 \%$ and insurance companies with ROA higher than $2 \%$ (inclusive), there was a statistically significant difference between the average technical efficiency score in the BCC model (Table 11). Insurance companies with ROA less than $2 \%$ had an average technical efficiency score of 0.8687 . The average technical efficiency score of insurance companies with ROA higher than $2 \%$ (inclusive) was by 0.1046 higher. 
Tobit regression with dependent variable BCC score

\begin{tabular}{lccc}
\hline \multicolumn{1}{c}{ Coefficient of determination $\mathbf{1 6 . 2 4 \%}$} & Coefficient & t-statistic & Sign. \\
\hline Constant & 0.8687 & 35.0757 & 0.0000 \\
\hline ROA higher than 2 (inclusive) & 0.1046 & 2.9534 & 0.0051 \\
\hline
\end{tabular}

Source: own processing in Matrixer

The shape of the regression function with technical efficiency score as the dependent variable in the BCC model with dummy variables expressing the groups of insurance companies with ROA higher than $2 \%$ (inclusive) is

$$
\theta_{j i}=0.8687+0.1046 X_{1 j i}+\varepsilon_{j}
$$

where $X_{1 j i}=1$ if the insurance companies belong to the group with ROA higher (inclusive) than $2 \%$, otherwise $X_{1 j i}=0$.

Coefficient of determination of this model is of value $16.24 \%$. To assess the relevancy of the statistical significance of the difference between the averages technical efficiency scores of individual groups, we used the non-parametric Mann-Whitney U test. The results are shown in Table 12.

Table 12

Mann-Whitney U test

\begin{tabular}{lcc}
\hline & U & Sign. \\
\hline Group 1 vs. group 2 & 168 & 0.0536 \\
\hline
\end{tabular}

Source: own processing in Statistica

From the results, it can be said that the statistically significant difference of the average technical efficiency scores was not confirmed at the significance level of 0.05 .

Tobit regression (Table 13) coefficients with dummy variables by groups of ROE are not statistically significant.

Tobit regression with dependent variable BCC score

\begin{tabular}{lccc}
\hline \multicolumn{1}{c}{ Coefficient of determination $\mathbf{2 . 6 3 \%}$} & Coefficient & t-statistic & Sign. \\
\hline Constant & 0.9100 & 43.2273 & 0.0000 \\
\hline ROE less than 5 & -0.0550 & -1.1025 & 0.2775 \\
\hline
\end{tabular}

Source: own processing in Matrixer

The null hypotheses stating that the efficiency of insurance companies in the BCC model is influenced by the group formed based on return on equity has not been confirmed. 


\section{DISCUSSION AND CONCLUSIONS}

The main research hypothesis of this article was that there is a significant relationship between efficiency and profitability of insurance company. Regarding our hypothesis in the introduction section, the relationship between the technical efficiency score in the CCR model and the group formed based on return on assets and the group formed based on return on equity was not confirmed.

Statistically significant differences between averages technical efficiency score in the CCR model in a group of insurance companies with ROA $\langle 1 \%, 2 \%)$ a technical efficiency score in the CCR model in a group of insurance companies with ROA equal or higher than 2 has been confirmed. Insurance companies with ROA equal or higher than 2 achieved higher average efficiency score in the CCR model that the insurance companies in a group with ROA $\langle 1 \%, 2 \%)$.

The relationship between the technical efficiency score in the BCC model and all groups formed based on return on assets and all groups formed based on return on equity was not confirmed. The linear relationship between the values of the technical efficiency score in the CCR and BCC models and the values of ROA, ROE and assets was not confirmed.

The same results about the influence of ROE on the level of technical efficiency, which Huang and Eling (2013) stated in their study, cannot be confirmed for the Slovak insurance market.

However, our study has some limitations. Data on the insurance companies were drawn from various sources - from the annual reports of individual insurance companies. This fact increases the possibility of distortion of the resulting technical efficiency scores.

Suggestions for further research include tracking the ROA and ROE impact to a level of technical efficiency over a longer time horizon. Possible findings may be important for the management of insurance companies as they can help them identify the mutual links that exist between the indicators and thereby improve the position of the insurance company on the insurance market.

\section{ACKNOWLEDGMENTS}

The article is part of a research project funded by the Scientific Grant Agency of the Ministry of Education, Science, Research and Sport of the Slovak Republic and the Slovak Academy of Sciences VEGA 1/0208/14 Insurance Market and Insurance Companies Efficiency.

\section{REFERENCES}

Barros, C. P., Nektarios, M., \& Assaf, A. (2010). Efficiency in the Greek insurance industry. European Journal of Operational Research, 205(2), 431-436.

Batir, T. E., Volkman, D. A., \& Gungor, B. (2017). Determinants of bank efficiency in Turkey: Participation banks versus conventional banks. Borsa Istanbul Review, 17(2), 86-96.

Berger, A. N., \& Humphrey, D. B. (1997). Efficiency of financial institutions: International survey and directions for future research. European Journal of Operational Research, 98(2), 175-212.

Borges, M. R., Nektarios, M., \& Barros, C. P. (2008). Analysing the efficiency of the Greek life insurance industry. European Research Studies, 11(3), 35-52.

Branka, J., \& Mihelja, Z., M. (2013). Banks and insurance companies efficiency indicators in the period of financial crisis: the case of the republic of Croatia. Ekonomska Istrazivanja, 26(1), 203-223.

Charnes, A., Cooper, W. W., \& Rhodes, E. (1978). Measuring the efficiency of decision-making units. European Journal of Operational Research, 2(6), 429-444.

Delhausse, B., Fecher, F., Perelman, S., \& Pestieau, P. (1995). Measuring productive performance in the non-life insurance industry: the case of French and Belgian markets. Tijdschrift voor Economie en Management, 40(1), 47-69. 
Diacon, S. R., Starkey, K., \& O'Brien, C. (2002). Size and efficiency in European long-term insurance companies: An international comparison. The Geneva Papers on Risk and Insurance. Issues and Practice, 27(3), 444-466.

Donni, O., \& Fecher, F. (1997). Efficiency and productivity of the insurance industry in the OECD countries. Geneva Papers on Risk and Insurance. Issues and Practice, 22(4), 523-535.

Eling, M., \& Luhnen, M. (2010). Efficiency in the international insurance industry: A cross-country comparison. Journal of Banking \& Finance, 34(7), 1497-1509.

Fandel, P. (2001). Environmental factors in efficiency assessment in agriculture. Economic and Managerial Aspects Sustainable Development of Agriculture. Nitra. Retrieved from http://spu.fem.uniag.sk.

Finstat. (2015). Database of Data. Retrieved from http://finstat.sk.

Greene, W. H., \& Segal, D. (2004). Profitability and efficiency in the US life insurance industry. Journal of Productivity Analysis, 21(3), 229-247.

Huang, W., \& Eling, M. (2013). An efficiency comparison of the non-life insurance industry in the BRIC countries. European Journal of Operational Research, 226(3), 577-591.

Hussels, S., \& Ward, D. R. (2007). The Impact of deregulation on the German and UK life insurance markets: an analysis of efficiency and productivity between 1991-2002. Retrieved from https://dspace.lib.cranfield.ac.uk/bitstream/1826/3947/1/Impact of deregulation on the German and UK_life_insurance_markets-RP4-07.pdf.

Insurance Companies. (2013). Annual Reports 2013.

Insurance Companies. (2015). Annual Reports 2015.

Jablonský, J., \& Dlouhý, M. (2004). Models for evaluation of production units' efficiency. Professional Publishing, Prague.

Jurčević, B., \& Žaja, M. M. (2013). Banks and insurance companies efficiency indicators in the period of financial crisis: The case of the Republic of Croatia. Economic Research-Ekonomska Istraživanja, 26(1), 203-224.

Klumpes, P. J. (2004). Performance benchmarking in financial services: Evidence from the UK life insurance industry. The Journal of Business, 77(2), 257-273.

Singh, D., \& Fida, B., S. (2015). Technical efficiency and its determinants: an empirical study on banking sector of Oman. Problems and Perspectives in Management, 13(1), 168-175.

Xiping, W., \& Yuesheng, L. (2007). Banking efficiency in China: application of DEA and Tobit Analysis. In International Conference of Management Science and Engineering of IEEE. Retireved from http://www.seiofbluemountain.com/upload/product/201001/1263801732sipnzhnd.pdf.

Yakob, R., Yusop, Z., Radam, A., \& Ismail, N. (2014). Two-stage DEA method in identifying the exogenous factors of insurers' risk and investment management efficiency. Sains Malaysiana, 43(9), 1439-1450.

Yao, S., Han, Z., \& Feng, G. (2007). On technical efficiency of China's insurance industry after WTO accession. China Economic Review, 18(1), 66-86.

Zimková, E. (2015). Technical efficiency and super-efficiency of the insurance sector in Slovakia. Acta Universitatis Agriculturae et Silviculturae Mendelianae Brunensis, 63(6), 2205-2211. 